\title{
Intraspecific competition in the ant Camponotus cruentatus: should we expect the 'dear enemy' effect?
}

\author{
RAPHAËL BOULAY*, XIM CERDÁ*, TOVIT SIMON†, MARÍA ROLDAN \& ABRAHAM HEFETZ† \\ *Estación Bioló gica de Doñana, Consejo Superior de Investigaciones Cientificas \\ yDepartment of Zoology, George S. Wise Faculty of Life Sciences zDepartamento \\ de Biología Animal y Ecología, Universidad de Granada
}

\begin{abstract}
The mechanisms of competition and resource domination were analysed in the Mediterranean ant Camponotus cruentatus. In a plot located in southern Spain mature colonies are overdispersed, which is indicative of territoriality in other species. Unexpectedly, however, workers from neighbouring colonies commonly foraged in areas that overlapped by more than $44 \%$. This suggests that while mature colonies possibly prevent the establishment of new colonies in the vicinity of their nests, they do not limit the intrusion of alien foragers. In contrast, rich food sources located in common foraging areas are aggressively defended, generally leading to their domination by the nest that discovered them first. Resource exploitation further requires rapid recruitment of foragers and soldiers to transport food as well as to exclude competitors. Complementary to the field experiments we conducted laboratory bioassays to assess intercolonial aggression. Group encounters showed that workers of C. cruentatus were equally aggressive towards alien ants irrespective of whether they were sympatric neighbours (and had possibly had contact), sympatric nonneighbours (which had probably had no contact), or allopatric. This was corroborated by analysis of the hydrocarbons that generally serve as colony recognition cues. This mixture, which contains an unusual proportion of trimethylalkanes, showed important colony specificity. The high intraspecific aggression shown indiscriminately by workers indicates that the 'dear enemy' effect does not exist in this species and suggests that scarce resources are worth defending against intraspecific competitors. We discuss several proximate and ultimate constraints that may prevent the general occurrence of this process in ants.
\end{abstract}

Keywords: aggressive interactions; Camponotus cruentatus; colony integrity; cuticular hydrocarbons; intraspecific competition; Mediterranean ant; nestmate recognition; social insects

The populations of many ant species and the spatial distribution of their nests are often controlled by densitydependent competitive processes (Hölldobler \& Wilson 1990). In the Australian meat ant, Iridomyrmex purpureus, high colony density increases intraspecific competition whereby colonies aggressively exclude each other (Thomas et al. 1999). On the other hand, experimental removal of all colonies of the red imported fire ant, Solenopsis invicta,

Correspondence: R. Boulay, Estación Biológica de Doñana, Consejo Superior de Investigaciones Cientificas, Avda Maria Luisa s/n, 41013 Sevilla, Spain (email: boulay@ebd.csic.es). T. Simon and A. Hefetz are at the Department of Zoology, George S. Wise Faculty of Life Sciences, Ramat Aviv, Tel Aviv, Israel. M. Roldan is at the Departamento de Biología Animal y Ecología, Universidad de Granada, 18071 Granada, Spain. from study plots was followed by a rapid population recovery due to the emigration of nearby colonies. At low nest density such migrating colonies have better chances of establishment, and enhanced survival and growth rates (Adams \& Tschinkel 2001). Aggressive intraspecific competition is assisted by the ants' ability to discriminate between nestmates and alien conspecifics, which allows workers to maintain colony insularity, in which on the one hand altruism is directed to often highly related nestmates (Jaisson 1991; Lenoir et al. 1999), while on the other hand domination of important resources like food or nest site is obtained by aggression directed at alien con- or heterospecific. Nevertheless, the lack of conspecific aggression, but not interspecific aggression (Errard et al. 2006) is a cornerstone in the evolution of unicoloniality (Chapman \& Bourke 2001; Chapuisat et al. 2005) and explains much of the recent invasions by tramp species 
(Holway et al. 1998; Suarez et al. 1999; Astruc et al. 2001; Giraud et al. 2002; Le Breton et al. 2004).

In their natural range, mature societies often defend an exclusive area around their nest where they aggress alien ants and prevent the establishment of other colonies of the same species (Ryti \& Case 1986; Cushman et al. 1988; Breed et al. 1990; Nichols \& Sites 1991; Wiernasz \& Cole 1995). One important consequence is that, on a local scale, mature nests are frequently overdispersed rather than aggregated or randomly distributed. In various harvester ants (Pogonomyrmex spp.), the wood ant, Formica rufa, and the neotropical ant Ectatomma ruidum, such nest distribution allows mature colonies to forage on nonoverlapping areas or trunk trails, which reduces the number of aggressive interactions between conspecific neighbours (Hölldobler 1974; Skinner 1980; Levings \& Franks 1982; Breed et al. 1990). Random nest distribution occurs in some species like Cataglyphis cursor, in which the foraging ranges of neighbouring societies widely overlap (Lenoir et al. 1990). However, in this latter species alien workers are quite tolerant and can feed peacefully at the same food source.

To reduce the cost of territorial defence, some species delineate areas around their nest with scent marks that repel aliens (Jaffe \& Puche 1984; Cammaerts \& Cammaerts 1996; Devigne \& Detrain 2002; Devigne et al. 2004). True physical fights can also be replaced by ritualized displays performed upon encounters with alien workers at the territory boundaries (Hölldobler 1976; Mercier et al. 1997; Pfeiffer \& Linsenmair 2001; van Wilgenburg et al. 2005). Finally, decreased aggressiveness towards nonnestmates is sometimes typical between neighbours that nevertheless remain highly aggressive towards allopatric or nonneighbour conspecific ants. This process resembles the so-called 'dear enemy' effect described in a variety of vertebrates and invertebrates (Fisher 1954; Rosell \& Bjorkoyli 2002; Husak \& Fox 2003; Leiser 2003). For ants, reduced aggression between neighbours was shown in Acromyrmex octospinosus (Jutsum et al. 1979), Leptothorax nylanderi (Heinze et al. 1996), Pheidole tucsonica and Pheidole gilvescens (Langen et al. 2000), Formica pratensis (Pirk et al. 2001) and Cataglyphis fortis (Knaden \& Wehner 2003).

In theory, two mechanisms could explain the 'dear enemy' effect. First, it may derive from habituation following repeated encounters between neighbouring ants while foraging. Although laboratory studies support this mechanism (Langen et al. 2000), whether it actually occurs in the field and the way in which it may transfer from the individual to colony level remain unclear. Moreover, repeated encounters between neighbours may increase aggression rather than reduce it, as in Pogonomyrmex barbatus (Gordon 1989), I. purpureus (Thomas et al. 1999) and Pristomyrmex pungens (Sanada-Morimura et al. 2003). Elevated aggression following repeated encounters may also occur in invasive Argentine ant in which Thomas et al. (2006) reported that workers collected at the boundary between pairs of Californian supercolonies were more aggressive to each other than workers collected further inside the supercolonies.

Second, the recognition cues of colonies living in the same area may be more similar than those of allopatric colonies (e.g. F. pratensis, Pirk et al. 2001). A large body of evidence now shows that these cues comprise a mixture of cuticular hydrocarbons (Vander Meer \& Morel 1998; Lahav et al. 1999; Lenoir et al. 1999; Wagner et al. 2000; Ozaki et al. 2005), the composition of which is influenced by the environment and the genetic background. Investigations on several species (i.e. Cataglyphis niger, Pachycondyla apicalis, Camponotus fellah, Aphaenogaster senilis) have shown that this mixture undergoes continuous homogenization among colony members through social interactions (Soroker et al. 1995; Soroker et al. 1998; Boulay et al. 2000; Lenoir et al. 2001; Boulay et al. 2004). Therefore, reduced genetic differences between neighbouring colonies, together with similarities in nesting material and food, might hamper chemical discrimination and reduce internest aggression.

The present study analyses the mechanisms of intraspecific competition in Camponotus cruentatus, a dominant species in the western Mediterranean basin. After a nuptial flight the single queen founds a new colony that matures to adulthood within a few years, comprising several thousand workers and producing hundreds of sexuals annually. Subterranean nests are monodomous and can occupy a surface of $2 \mathbf{e} 4 \mathrm{~m}^{2}$ with several entrances (R. Boulay \& X. Cerdá , personal observation). Although workers are important collectors of aphid honeydew, they are also opportunist foragers that feed on bird faeces, dead insects and myrmecochorous seeds (Alsina et al. 1988; Boulay et al. 2005). We estimated the spatial distribution of nests and the degree of overlap of their foraging areas in an experimental plot. We predicted that an important overlap of foraging areas would be found if mature colonies were randomly distributed, but not if they were overdispersed. Then, by offering a rich food source at a spot where two foraging areas overlap (near the edge of each nest's foraging range), we tested whether one colony monopolizes the food source or whether overt fighting over the source occurs. Finally, we carried out a series of behavioural tests and chemical analyses to test the 'dear enemy' effect and the geographical distance-dependence of hydrocarbon profile differentiation in this species.

\section{METHODS}

\section{Study System}

Fieldwork was conducted during the summer (late Junee early August) of 2004 in a plot measuring $50 \times 50 \mathrm{~m}$ located in Sierra de Cazorla (South Spain: $37^{\circ} 56^{\circ} \mathrm{N}, 2^{\circ} 52^{\circ} \mathrm{N}$ ) at about $1460 \mathrm{~m}$ elevation. It consisted of an open field with sparsely distributed pine (Pinus nigra) and oak (Quercus rotundifolia) trees and shrubs (mostly Quercus ilex, Juniperus oxycedrus and Rubus ulmifolius). The climate at Sierra de Cazorla is typical of Mediterranean mountains, with long hot, dry summers and cold wet winters. During the period of observations C. cruentatus ceased foraging at midday when ground temperature exceeded $40^{\circ} \mathrm{C}$. All field experiments and observations were therefore conducted during mornings from 0800 to 1200 hours (i.e. between 1 and $5 \mathrm{~h}$ after sunrise).

\section{Nest Density, Foraging Area and Food Domination}

To map nest distribution and colony foraging area, the study plot was divided into 100 grid squares measuring 
$5 \times 5 \mathrm{~m}$, each of which was scrutinized until a forager was located. To induce the forager to return to its nest it was hand-fed with a small piece of bait (e.g. sausage or tuna fish) and tracked back to the nest. If a worker was not spotted after $5 \mathrm{~min}$ we proceeded to the next square. This process was repeated over a period of 10 consecutive days during which each grid-square was scanned six times. Ant departure-spot and nest entrance were geo-referenced, and nest location was mapped using Arcview GIS v. 3.2 (ESRI, Redlands, CA). Colonies were then categorized as either established or incipient using the following criteria: the number of workers tracked back to each nest, the presence of soldiers guarding the nest entrance, and the existence of a permanent traffic of foragers entering and exiting the nest. Colony survival was checked after 1 year (summer 2005) by monitoring the ants' activity after depositing small pieces of tuna fish at the nest entrance. We never observed colony relocation and are unaware of such being reported in this or any close species of the same genus.

Spatial nest distribution was compared with a random distribution using the method of Clark \& Evans (1954). In brief, this method computes a C statistics based on the distance to the nearest neighbour and nest density in the plot and compares it with a $\mathrm{Z}$ distribution to test whether the observed distribution is more aggregated or more dispersed than expected at random. To estimate the $95 \%$ minimum convex polygons (MCPs) of nests for which we had more than 10 ant departure-spots (Michener 1979) we used the Home Range extension for Arcview (available at http://www.blueskytelemetry.co.uk/). These polygons reflect the minimum area around the nest in which at least $95 \%$ of the workers forage. The proportion of overlap between MCPs was used to estimate overlap in foraging areas of neighbouring nests.

To investigate whether a food patch was dominated by one colony or was shared by ants from neighbouring colonies, we placed bait (minced sausage) at a spot in their overlapping foraging areas. A small dot of paint was gently deposited on the abdomen of the first workers that discovered the bait to track them back to their nest. The number of ants present at each recruitment event for both colonies was counted for $3 \mathrm{~h}$ after food discovery. For each pair of nests, three to five replicates were performed with at least 2 days interval between replicates. We estimated the relative recruitment effort of a colony as the percentage of workers it recruited during a single experiment with respect to the total number of recruits of this colony in all the replicates. The relative recruitment effort of a colony was then regressed against the relative recruitment effort of its counterpart using a generalized linear model for repeated measures. The null hypothesis was that the relative recruitment effort of a colony was independent of that of its counterpart (i.e. neighbours share food patch). To that end we used the GENMOD procedure for SAS v. 8.0 (SAS Institute Inc., Cary, NC) with the negative binomial error distribution and Logit link function.

\section{Behavioural Tests}

To test the 'dear enemy' hypothesis we measured the aggression between neighbouring and distant nests in the laboratory. Thirty-one groups of five resident ants were collected from 18 established colonies (at least one group per colony) of the study plot and installed in containers measuring $17 \times 17 \times 5 \mathrm{~cm}$, the walls of which were talcum coated to prevent the ants from escaping. Each group of residents was exposed to a nestmate intruder (control), to an alien nonneighbour intruder, and to an alien neighbour intruder (n $1 / 42$ ), an alien allopatric intruder (n $1 / 42$ ) or both (n $1 / 427)$. The alien allopatric intruder was collected from one of 10 colonies belonging to a population located more than $30 \mathrm{~km}$ away. At least $45 \mathrm{~min}$ elapsed between two consecutive tests using the same group of residents. The ants were allowed to calm down and return to normal exploratory or resting activity before the test began. The filter paper lining the container was replaced between consecutive tests. All the workers were field collected near their nest entrance a few hours before the tests. Intruders were marked with a dot of paint on the abdomen and allowed to settle for $1 \mathrm{~min}$ before the encounters by keeping them in a small compartment that was removed at $t^{1 / 4} 0$. The interactions between the five residents and the intruder were then recorded every $30 \mathrm{~s}$ for $10 \mathrm{~min}$. Six interactions were clearly identified: antennal exploration, grooming, trophallaxis, threat (a resident bends its abdomen forward and opens its mandibles in the direction of the intruder), bite, and duel (a resident seizes the intruder by the mandibles and starts to pull backward to immobilize it). An aggression score was calculated for each test by dividing the number of aggressive interactions (threats, bites and duels) by the total number of interactions. The GENMOD procedure for SAS v. 8.0 was used to fit a generalized linear model to the aggression score with the binomial error distribution and Logit link function. The dependent variables were the type of intruder (within-subject factor), the order in which the residents encountered the intruders, and their colony of origin (both between-subject factors). The Lsmeans statement was used to estimate differences between levels of the main factors.

\section{Chemical Analyses}

Ants were captured at their nest entrance and held at $9^{\circ} \mathrm{C}$ for $15 \mathrm{~min}$ to calm down and thereafter frozen at $-20^{\circ} \mathrm{C}$. Dissected postpharyngeal glands (PPGs) were immersed in $50 \mathrm{ml}$ of hexane and thorax washes were carried out for $30 \mathrm{~min}$ in $500 \mathrm{ml}$ of hexane. Initial identification of cuticular and PPG hydrocarbons was achieved by gas chromatography coupled to mass spectrometry (EI mode at $70 \mathrm{eV}$ ) on three representative samples, each of which constituted a pool of 15 individuals. Compound separation was achieved using a DB-5 fused silica capillary column that was temperature programmed from $150^{\circ} \mathrm{C}$ to $300^{\circ} \mathrm{C}$ at $5^{\circ} \mathrm{C}$. Compounds were identified by their mass fragmentation pattern as well as by comparison with synthetic n-alkanes.

Individual PPG analyses were performed by gas chromatography coupled to flame ionization detection using the same chromatographic conditions. We analysed a total of 48 workers from four colonies, three of which (18, 6 and 15) 
were sympatric and located at the study plot while the fourth (99) was from a different population located about $30 \mathrm{~km}$ from the study plot (allopatric). For colony 18 we sampled ants from each of two different entrances (a and b) about $1 \mathrm{~m}$ apart (nestmates). Colony 6 had high overlap in the foraging area with colony 18 (sympatric neighbours) while colony 15 did not share the foraging area with either colony 18 or colony 6 (sympatric nonneighbours).

To estimate similarities between individual PPG profiles we performed a cluster analysis using Ward's (1963) method without a priori assigning workers a colony identity. We selected 41 peaks, whose average relative proportion across all samples exceeded $1 \%$. To eliminate biased effects of dominant compounds and nonindependence of the proportions, the difference between the surface of a peak and this peak's average surface across all samples was divided by the respective standard deviation (Quinn \& Keough 2002). The standardized variables were independent of each other and had a zero mean and one unit standard deviation. A discriminant function analysis was conducted to confirm the results of the cluster analysis. The significance of group separation according to their squared Mahalanobis distances was tested by mean of analysis of variance.

\section{RESULTS}

\section{Nest Density, Foraging Area and Food Domination}

A total of 533 workers were tracked back to their nests during summer 2004, 486 of which belonged to 18 nests (mean T SE: 27 T 14; range: 13e48) located in or near the limits of the plot (Fig. 1). These nests had clearly been established for more than 2 years judging by the permanent traffic of foragers going in and out, and the presence of soldiers guarding the entrance. By contrast, 21 ants belonged to 10 colonies that neither showed regular traffic of foragers nor had soldiers, suggesting that they were incipient colonies founded during the previous nuptial flight (midsummer 2003). All 18 established nests, but only seven incipient ones, were also found in 2005. The remaining 26 ants that were tracked back were scouts from nests located at least $10 \mathrm{~m}$ away from the plot boundaries.

Within the study plot, the 18 established nests tended to be overdispersed ( $\mathrm{C} 1 / 44.57 ; \mathrm{P}<0.0001)$. Even when the seven incipient colonies that survived in 2005 were included in the analysis, the average distance separating two neighbouring nests was still larger than expected from random (C 1/4 2.56; $\mathrm{P}<0.005$ ). The average distance separating two established neighbouring nests was $10.0 \mathrm{~T} 0.6 \mathrm{~m}$ (mean T SE) and never less than $7 \mathrm{~m}$. The distribution of distances to the closest neighbour was not normal but right-skewed towards large distances (ShapiroeWilk W 1/4 0.88, P 1/4 0.0302). The polygon surface delineating the area in which $95 \%$ of the ants from a single, large colony foraged was on average 156 T $33 \mathrm{~m}^{2}$ (mean T SE; Fig. 1). Such colonies shared 44.3 T 8.5\% (mean T SE; minemax: 0e97\%) of their foraging area with one or more neighbours. Ants from neighbouring colonies repeatedly patrolled these common areas and thus could compete for the same food sources.

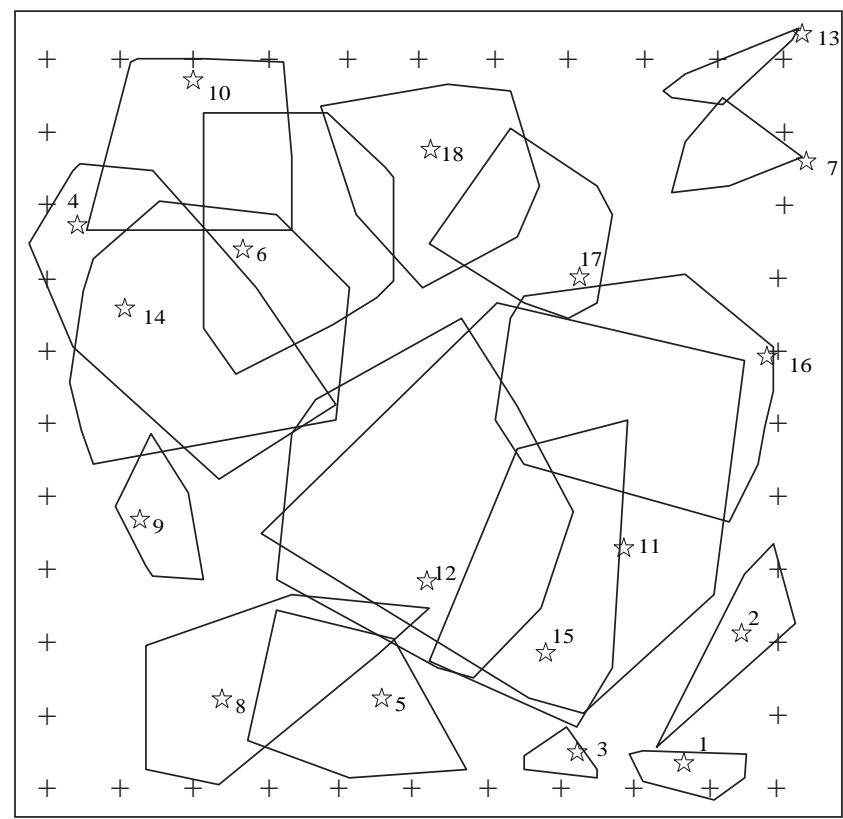

Figure 1. Map of the 18 major nests localized on or near the $50 \times 50 \mathrm{~m}$ studied plot. The polygons are 95\%MCP figuring the area within which $95 \%$ of the workers of a given nest forage. The crosses delimit the plot.

Bait placed on the border between foraging areas belonging to neighbouring nests was rapidly discovered following the onset of daily activity. The first ants generally inspected the bait and then transported part of it to the nest. The same ant (as judged by it marked abdomen) often returned with a group of $4.48 \mathrm{~T} 0.22$ recruits (mean T SE; range: 1 e13 recruited ants). The relative recruitment effort of two neighbouring colonies was not independent but negatively correlated (b $1 / 4-3.1182$, $\left.\mathrm{Z}_{17} 1 / 4-3.67, \mathrm{P} 1 / 40.0002\right)$. For example, while colonies 10 and 4 recruited approximately the same total number of workers over four tests (116 and 106, respectively), their relative recruitment effort was negatively correlated: when colony 4 recruited numerous workers, 10 did not and vice versa. In 14 out of 18 tests this asymmetry resulted in complete domination of the bait by only one colony, the identity of which, however, differed between tests. In 10 cases, the colony that discovered the food bait first was eventually the dominant one. Resource domination was generally attained by recruiting soldiers that patrolled the site and aggressively prevented the approach of nonnestmates, which could reach the bait only by means of swift sneaking. Only in four tests did both nests recruit nestmates at a more symmetric rate, leading to a full-scale battle that ended when, after several recruitments, workers from one nest clearly outnumbered those of the other and forced them to retreat.

\section{Behavioural Tests}

The results of the behavioural tests conducted in the lab indicated that resident groups did not respond aggressively to the introduction of a nestmate ant into the arena 
and mostly shared trophallaxis, groomings or antennations. By contrast, residents were always very aggressive towards alien ants, irrespective of whether they came from an allopatric, sympatric or neighbouring nest (Fig. 2; $\left.\mathrm{C}_{3}^{2} 1 / 422: 84, \quad \mathrm{P}<0.0001\right)$. Neither the order in which the different types of encounters were performed, nor the colony of origin of the resident ants significantly affected the aggression score $\left(c_{3}^{2} 1 / 46: 45, \quad P<0.0915\right.$ and $c_{17}^{2} 1 / 415: 42$, $\mathrm{P}<0.5650$, respectively).

\section{Chemical Analyses}

There was high congruency between cuticular washes and PPG extracts (Fig. 3). Sixty-four hydrocarbon peaks were identified, revealing an atypical profile for ants in possessing high proportions of trimethylalkanes (the two largest peaks belonged to 5,11,15-trimethylhentriacontane and 5,11,15-trimethyltritriacontane). The thoracic washes also contained four esters of fatty acids (dodecyl dodecanoate, dodecyl tridecanoate, tetradecyl dodecanoate, tetradecyl tridecanoate) that may have originated from Dufour's gland, which also contains high concentrations of these esters (data not shown). It is not known whether the ants projected these compounds during their manipulation or if they normally bear them on their cuticle. The cluster analysis revealed a clear separation on the basis of colony identity (Fig. 4). None the less, colonies 18, 6 and 15, all located on the study plot, were also clearly separated from the allopatric colony (99). Within the study plot colonies 6 and 15 clustered together, suggesting that their profiles were more similar to each other than to that of colony 18. Ants from colony 18, except for one worker that was misclassified, clustered together regardless of the entrance at which they had been collected ( $a$ or b). Discriminant function analysis confirmed the significant difference (measured with squared Mahalanobis distances) between the hydrocarbon profiles of workers from colonies 18, 6, 15 and 99 (data not shown; F 1/4 1.41, $\mathrm{P}<0.0001)$. Nevertheless, workers collected at nest entrance $18 \mathrm{a}$ and $18 \mathrm{~b}$ were not significantly discriminated (P 1/4 0.204). The first extracted root, which explained $72 \%$ of the total variance, opposed allopatric colonies,

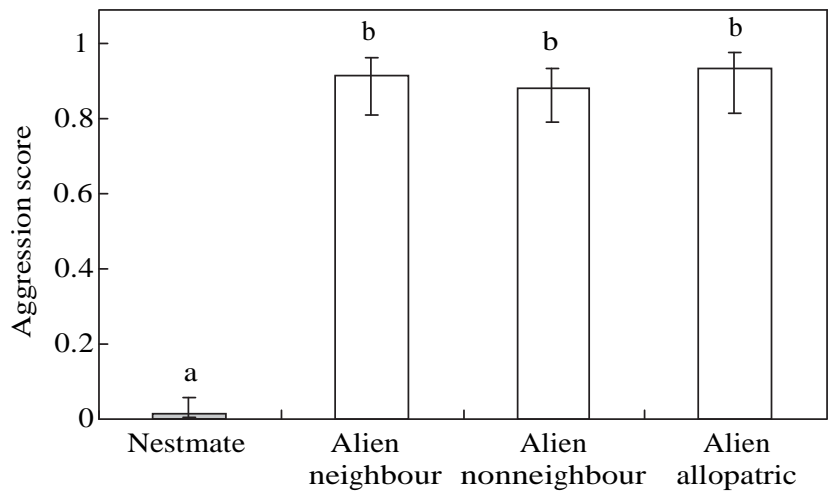

Figure 2. Aggression scores (model-adjusted means T 95\% confidence limits) of the four types of encounters. Different letters denote significant differences. while the second extracted root, which explained $19 \%$ of the variance, opposed sympatric colonies.

\section{DISCUSSION}

The ant C. cruentatus is a very common and widespread species in mountainous regions of the western Mediterranean basin, where it generally dominates and displaces its main competitors (e.g. Cerdá et al. 1997). Its abundance in the study region is evidenced by the fact that at least one worker could be found in $88.8 \%$ of the six scan-surveys that were performed in each of the 100 grid squares in our study plot. Large nests were overdispersed, which suggests that they competitively exclude new foundations by direct aggression of incipient colonies, through a more efficient food exploitation, or both. Our first prediction was that overdispersion of nests would lead to a reduced overlap of foraging areas as is common in other dominant ant species (Hölldobler 1974; Skinner 1980; Levings \& Franks 1982; Breed et al. 1990). Surprisingly, however, the 18 established colonies of $\mathrm{C}$. cruentatus that were localized on our study plot foraged on areas that overlapped by more than $44 \%$. This is in contrast, for example, to Ectatomma ruidum, another species in which nests are regularly distributed and foraging areas do not overlap at all (Breed et al. 1990).

This large overlap suggests that alien C. cruentatus workers frequently compete for the same resources. In particular, this may occur when the food source is too large to be exploited by a single individual (e.g. a clump of myrmecochorous seeds or a bird faeces), which therefore recruits nestmates. This was simulated in our study by depositing large pieces of bait at the intersection of two neighbouring colony foraging ranges. By marking the first ants that discovered the food, we observed that they often returned to the source accompanied by up to 13 nestmates. This mode of group recruitment, which was first described in Camponotus paria (Hingston 1929), also occurs in Camponotus socius (Hö lldobler 1971; Kohl et al. 2001) and Camponotus sylvaticus (Cerdá et al. 1997; R. Boulay, unpublished data). Each recruited worker can recruit further workers, which rapidly leads to multiple groups travelling between the nest and the source. The recruitment effort of the two colonies that shared the area where the bait was deposited was not independent but negatively correlated, which may denote resource domination by one colony. However, from our observations of repeated encounters it is clear that there was no monopolization by specific nests but, rather, that domination seems to be linked to the nest origin of the scout that found the resource first, and to the fact that the first ants recruited were generally soldiers, which did not participate in food collection but patrolled around the source and drove away any approaching alien ants. This mechanism may give a competitive advantage to large colonies that have more scouts and may be able to discover a new source more quickly than small colonies. The negative correlation between the recruitment efforts of two neighbouring nests suggests that foragers that discovered a resource that was already dominated by a neighbouring colony did not recruit. A more dramatic 


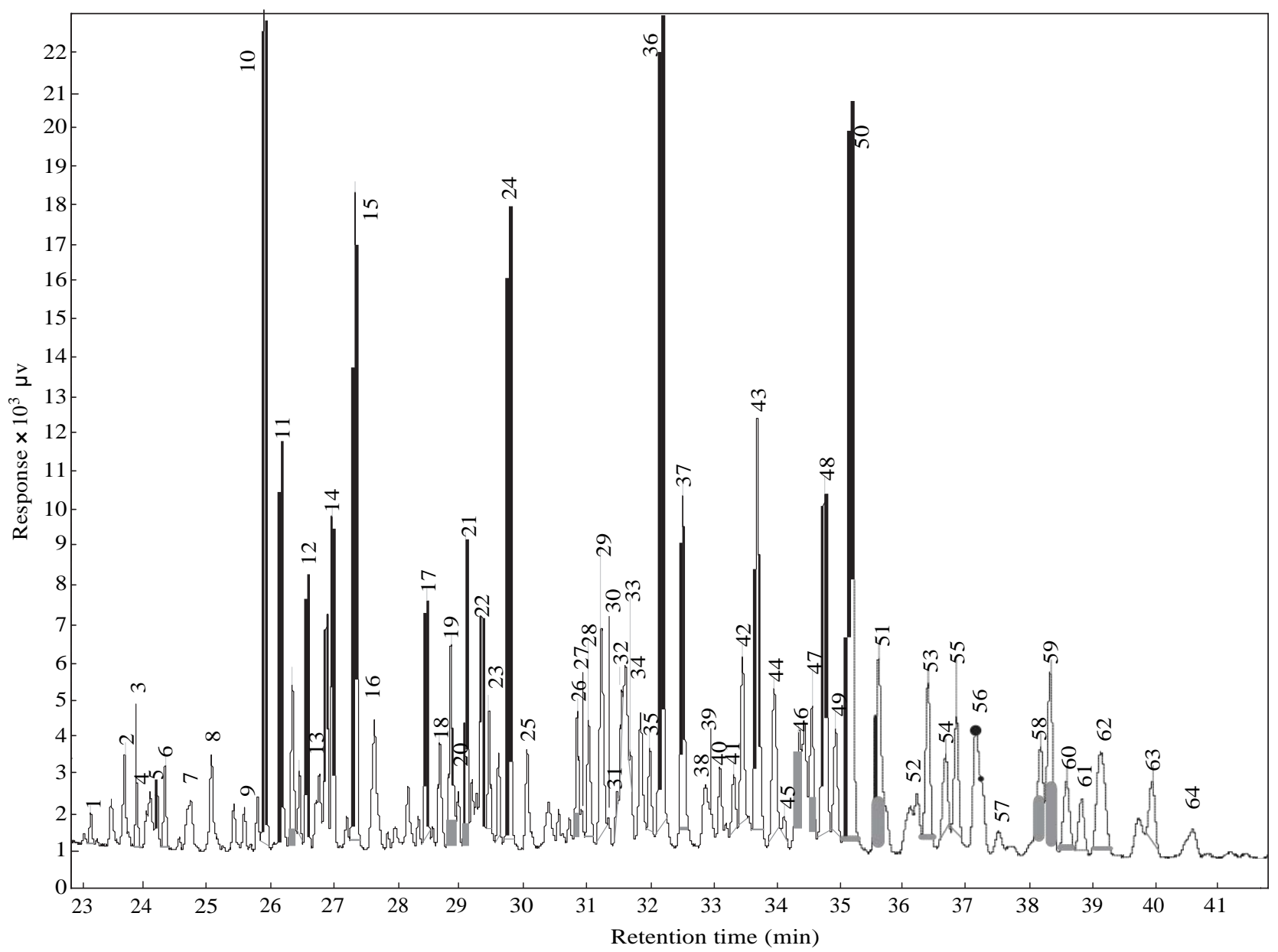

Figure 3. Chromatogram of PPG secretions of C. cruentatus. Compounds in bolds were used in statistical analysis. (1) Pentacosane; (2) 9methyl pentacosane; (3) 7-methyl pentacosane; (4) 5-methyl pentacosane; (5) 3-methyl pentacosane; (6) 5,9-dimethyl pentacosane; (7) 10-methyl hexacosane; (8) 10,12-dimethyl hexacosane; (9) heptacosane; (10) 11,13,17-trimethyl pentacosane; (11) 11-methyl heptacosane; (12) 5-methyl heptacosane; (13) 3-methyl heptacosane; (14) 12 methyl octacosane; (15) 5,9-dimethyl heptacosane; (16) 3,9-dimethyl heptacosane; (17) 5,11,15-trimethyl heptacosane; (18) nonacosane; (19) 13-p15-methyl nonacosane; (20) 11-methyl nonacosane; (21) 5-methyl nonacosane; (22) 5,11-dimethyl nonacosane; (23) 7,11,13-trimethyl nonacosane; (24) 5,11,13-trimethyl nonacosane; (25) 3,11,13-trimethyl nonacosane; (26) 6-methyl triacontane; (27) 4-methyl triacontane; (28) 4,12,14 trimethyl triacontane; (29) 11-p9-methyl hentriacontane; (30) 7-methyl hentriacontane; (31) 5-methyl hentriacontane; (32) 11,15-dimethyl hentriacontane; (33) 7,11-dimethyl hentriacontane; (34) 5,11-dimethyl hentriacontane; (35) 7,11,15-trimethyl hentriacontane; (36) 5,11,15-trimethyl hentriacontane; (37) 3,11,15-trimethyl hentriacontane; (38) 10,14-dimethyl dotriacontane; (39) 6,10-dimethyl dotriacontane; (40) 6,12-dimethyl dotriacontane; (41) 4,12-dimethyl dotriacontane; (42) 6,12,16-trimethyl dotriacontane; (43) 412,16-trimethyl dotriacontane; (44) 11p13-methyl tritriacontane; (45) 7-methyl tritriacontane; (46) 5-methyl tritriacontane; (47) 7,11-dimethyl tritriacontane; (48) 5,13-dimethyl tritriacontane; (49) 7,11,15-trimethyl tritriacontane; (50) 5,11,15-trimethyl tritriacontane; (51) 3,11,15-trimethyl tritriacontane; (52) 8,14-dimethyl tetratriacontane; (53) 6,14-dimethyl tetratriacontane; (54) 4,14-dimethyl tetratriacontane; (55) 6,12,16-trimethyl tetratriacontane; (56) pentatriacontane; (57) 11-p13-methyl pentatriacontane; (58) 7-methyl pentatriacontane; (59) 7,15-dimethyl pentatriacontane; (60) 5,15-dimethyl pentatriacontane; (61) 7,13,17-trimethyl pentatriacontane; (62) 5,13,17-trimethyl pentatriacontane; (63) 8,16-dimethyl hexatriacontane; (64) 8,14-dimethyl hexatriacontane.

situation was observed on four occasions, when both competing colonies discovered the source almost simultaneously and did not stop recruiting until a full-scale battle broke out involving tens of workers. High levels of aggression between alien workers and the losses this can incur may have favoured the evolution of mechanisms preventing escalation of fights. During contests, we did not observe ritualized behaviours as described, for example for Camponotus gigas (Pfeiffer \& Linsenmair 2001) and other species (Hölldobler 1976; Mercier et al. 1997; van Wilgenburg et al. 2005). In C. cruentatus, resource-site marking may play a role in reducing the probability of fighting. While patrolling around the source, soldiers repeatedly touched the ground with the tip of their abdomen, possibly depositing a repellent aimed at alien conspecifics. None the less, whenever contact was made with alien ants it culminated in overt aggression with most threats developing into bites and the ejection of formic acid, which caused serious injury.

The high level of aggression among alien neighbours was confirmed by our laboratory bioassays. Maximum aggression was released between alien ants regardless of 


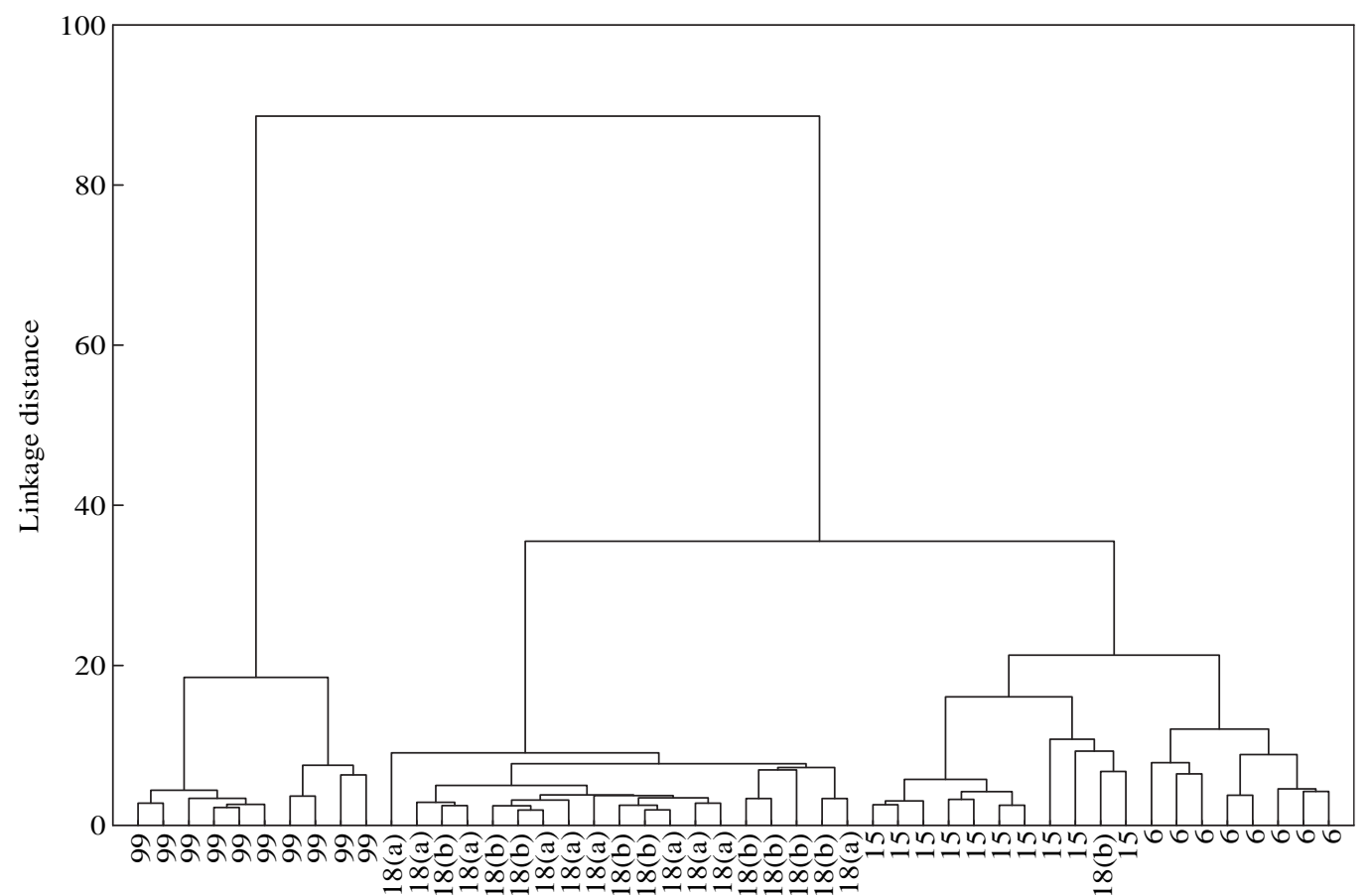

Figure 4. Dendrogram generated by the cluster analysis conducted on the PPG hydrocarbon profiles of 48 individuals from colonies $6,15,99$ and 18. For the latter, letters between parentheses identify two nest entrances where the ants were collected.

whether they were sympatric neighbours (that possibly have had contact while foraging previously), sympatric nonneighbours (colonies nesting less than $70 \mathrm{~m}$ apart but sufficiently distant not to have overlapping foraging area and very low probabilities of accidental contact while foraging), or allopatric ants (that belonged to different populations over $30 \mathrm{~km}$ away from the study plot). Similar independence between geographical distances and aggression as well as aggression between neighbouring nests were also described in Cataglyphis iberica (Dahbi et al. 1996). High aggression between C. cruentatus workers was accompanied by dissimilarities in cuticular hydrocarbon profiles among colonies. To date, multiple studies have shown that such mixtures serve as a colony recognition signal (Vander Meer \& Morel 1998; Lahav et al. 1999; Lenoir et al. 1999; Wagner et al. 2000; Ozaki et al. 2005). In the present study, the hydrocarbon profile of C. cruentatus was very similar among nestmates but clearly different among colonies, which may explain the aggressive rejection of all aliens. Given the behavioural results discussed above, this suggests that even a relatively low difference in recognition cues already generates the maximum level of aggression. Interestingly, sympatric colonies clustered separately from the allopatric colony. This might have been because of a greater similarity in environmental factors (e.g. food) that affect the hydrocarbon pattern (Buczkowski \& Silverman 2006), or to larger genetic differences among populations (Beye et al. 1998; Tsutsui et al. 2003).

In many territorial solitary vertebrates, individuals are able to adapt their aggressive behaviour to the identity of their competitors. For example, male wall lizards display strong aggressiveness towards new immigrants but such aggression declines once the neighbours have become familiar with each other and territories have been established (López \& Martín 2002). Although a similar 'dear enemy' effect has been described in eusocial insects (Jutsum et al. 1979; Heinze et al. 1996; Langen et al. 2000; Pirk et al. 2001; Knaden \& Wehner 2003), several proximate and evolutionary shortcomings may limit its general occurrence in social insects. The first pertains to the likelihood of learning the neighbours' recognition cues. Unlike long-lived solitary animals that repeatedly encounter their neighbours, ants frequently start foraging in the last weeks or days of their life, a period that may not be sufficient to acquire enough information on their neighbours' identity, especially if the probability of encounter is low. Moreover, the temporal plasticity of the recognition label (Provost et al. 1993; Boulay et al. 2000; Suarez et al. 2002) may further hamper the habituation process. Finally, there is no evidence that such information if learned by the individual forager can be transferred to nestmates. Even if these proximate shortcomings can be overcome, the ultimate cause for the 'dear enemy' effect in social insects remains questionable. It is hard to perceive why a reduction of aggressiveness among neighbours while maintaining a high level of aggression among nonneighbours would be selected for. The 'dear enemy' effect is expected to evolve when residents and intruders are of similar size, which frequently occurs in territorial vertebrates. However, in ant species like C. cruentatus, established colonies do not migrate and consequently are unlikely to encounter any unfamiliar competitor other than a new foundation, which can be easily dominated. Although different life history traits or ecological conditions (colony fission, budding, frequent nest relocation, reduced intraspecific density) may possibly 
promote the 'dear enemy' effect, they can also lead to the opposite, that is a higher aggression towards neighbours that threaten territorial integrity (Thomas et al. 1999; Sanada-Morimura et al. 2003; Thomas et al. 2006), or to a more general reduction of intraspecific aggression allowing rapid colonization of new environments (Holway et al. 1998; Giraud et al. 2002).

\section{Acknowledgments}

We thank Alain Lenoir and two anonymous referees for their helpful comments on this manuscript. Javier Juste kindly advised us for statistical analyses. Elena Angulo, Aaron Gove, Isabel Luque, Alberto Tinaut and Merav Vonshak provided important assistance in various aspects of the fieldwork. We are also grateful to Naomi Paz for editorial assistance. This work was supported by a grant from 'Ecodoca' (European Community-Access to Research Infrastructure action of the Improving Human Potential Programme in Doñana Biological Station) to A. H.

\section{References}

Adams, E. S. \& Tschinkel, W. R. 2001. Mechanisms of population regulation in the fire ant Solenopsis invicta: an experimental study. Journal of Animal Ecology, 70, 355e369.

Alsina, A., CerdÁ, X., Retana, J. \& Bosch, J. 1988. Foraging ecology of the aphid-tending ant Camponotus cruentatus (Hymenoptera, Formicidae) in a savanna-like grassland. Miscellania Zoologica, 12, $195 \mathbf{e} 204$.

Astruc, C., Malosse, C. \& Errard, C. 2001. Lack of intraspecific aggression in the ant Tetramorium bicarinatum: a chemical hypothesis. Journal of Chemical Ecology, 27, 1229e1248.

Beye, M., Neumann, P., Chapuisat, M., Pamilo, P. \& Moritz, R. F. A. 1998. Nestmate recognition and the genetic relatedness of nests in the ant Formica pratensis. Behavioral Ecology and Sociobiology, 43, 67e72.

Boulay, R., Soroker, V., Hefetz, A. \& Lenoir, A. 2000. Individuality in hydrocarbon production obliges Camponotus fellah workers frequent exchanges for colony integration. Animal Behaviour, 59, 1127 e1133.

Boulay, R., Katzav-Gozansky, T., Hefetz, A. \& Lenoir, A. 2004. Odour convergence and tolerance between nestmates through trophallaxis and grooming in the ant Camponotus fellah (Dalla Torre). Insectes Sociaux, 51, 55e61.

Boulay, R., Fedriani, J. M., Manzaneda, A. \& CerdÁ, X. 2005. Indirect effects of alternative food resources in an ant-plant interaction. Oecologia, 144, 72e79.

Breed, M. D., Abel, P., Bleuze, T. J. \& Denton, S. E. 1990. Thievery, home ranges, and nestmate recognition in Ectatomma ruidum. Oecologia, 84, 117e121.

Buczkowski, G. \& Silverman, J. 2006. Geographical variation in Argentine ant aggression behaviour mediated by environmentally derived nestmate recognition cues. Animal Behaviour, 71, 327e335.

Cammaerts, M. C. \& Cammaerts, R. 1996. Area marking in the ant Pheidole pallidula (Myrmicinae). Behavioural Processes, 37, 21e30.

CerdÁ, X., Retana, J. \& Cros, S. 1997. Thermal disruption of transitive hierarchies in Mediterranean ant communities. Journal of Animal Ecology, 66, 363e374.

Chapman, R. E. \& Bourke, A. F. G. 2001. The influence of sociality on the conservation biology of social insects. Ecology Letters, 4, 650 e662.
Chapuisat, M., Bernasconi, C., Hoehn, S. \& Reuter, M. 2005. Nestmate recognition in the unicolonial ant Formica paralugubris. Behavioral Ecology, 16, 15e19.

Clark, P. J. \& Evans, F. C. 1954. Distance to nearest neighbor as a measure of relationships in populations. Ecology, 35, 445 e 453.

Cushman, J. H., Martinsen, G. D. \& Mazeroll, A. I. 1988. Densitydependent and size-dependent spacing of ant nests e evidence for intraspecific competition. Oecologia, 77, 522e525.

Dahbi, A., CerdÁ, X., Hefetz, A. \& Lenoir, A. 1996. Social closure, aggressive behavior, and cuticular hydrocarbon profiles in the polydomous ant Cataglyphis iberica (Hymenoptera, Formicidae). Journal of Chemical Ecology, 22, 2173e2186.

Devigne, C. \& Detrain, C. 2002. Collective exploration and area marking in the ant Lasius niger. Insectes Sociaux, 49, 357e362.

Devigne, C., Renon, A. J. \& Detrain, C. 2004. Out of sight but not out of mind: modulation of recruitment according to home range marking in ants. Animal Behaviour, 67, 1023e1029.

Errard, C., Hefetz, A. \& Jaisson, P. 2006. Social discrimination tuning in ants: template formation and chemical similarity. Behavioral Ecology and Sociobiology, 59, 353e363.

Fisher, J. 1954. Evolution and bird sociality. In: Evolution as a Process (Ed. by A. C. H. Huxley \& E. B. Ford), pp. 71e83. London: Allen \& Unwin.

Giraud, T., Pedersen, J. S. \& Keller, L. 2002. Evolution of supercolonies: the Argentine ants of southern Europe. Proceedings of the National Academy of Sciences, U.S.A., 99, 6075e6079.

Gordon, D. M. 1989. Ants distinguish neighbors from strangers. Oecologia, 81, 198e200.

Heinze, J., Foitzik, S., Hippert, A. \& Hölldobler, B. 1996. Apparent dear-enemy phenomenon and environment-based recognition cues in the ant Leptothorax nylanderi. Ethology, 102, 510e522.

Hingston, R. W. G. 1929. Instinct and Intelligence. New York: Macmillan. Hölldobler, B. 1971. Recruitment behavior in Camponotus socius (Hym. Formicidae). Zeitschrift für Vergleichende Physiologie, 75, $123 \mathbf{e} 142$.

Hölldobler, B. 1974. Home range orientation and territoriality in harvesting ants. Proceedings of the National Academy of Sciences, U.S.A., 71, 3274e3277.

Hölldobler, B. 1976. Tournaments and slavery in a desert ant. Science, 192, 912e914.

Hölldobler, B. \& Wilson, E. O. 1990. The Ants. Cambridge, Massachusetts: Harvard University Press.

Holway, D. A., Suarez, A. V. \& Case, T. J. 1998. Loss of intraspecific aggression in the success of a widespread invasive social insect. Science, 282, 949e952.

Husak, J. F. \& Fox, S. F. 2003. Adult male collared lizards, Crotaphytus collaris, increase aggression towards displaced neighbours. Animal Behaviour, 65, 391e396.

Jaffe, K. \& Puche, H. 1984. Colony-specific territorial marking with the metapleural gland secretion in the ant Solenopsis geminata (Fabr.). Journal Insect Physiology, 30, 265e270.

Jaisson, P. 1991. Kinship and fellowship in ants and social wasps. In: Kin Recognition (Ed. by P. G. Hepper), pp. 60e93. Cambridge: Cambridge University Press.

Jutsum, A. R., Saunders, T. S. \& Cherrett, J. M. 1979. Intraspecific aggression in the leaf-cutting ant Acromyrmex octospinosus. Animal Behaviour, 27, 839e844.

Knaden, M. \& Wehner, R. 2003. Nest defense and conspecific enemy recognition in the desert ant Cataglyphis fortis. Journal of Insect Behavior, 16, 717e730.

Lahav, S., Soroker, V., Hefetz, A. \& Vander Meer, R. K. 1999. Direct behavioral evidence for hydrocarbons as ant recognition discriminators. Naturwissenschaften, 86, 246e249. 
Langen, T. A., Tripet, F. \& Nonacs, P. 2000. The red and the black: habituation and the dear-enemy phenomenon in two desert Pheidole ants. Behavioral Ecology Sociobiology, 48, 285e292.

Le Breton, J., Delabie, J. H. C., Chazeau, J., Dejean, A. \& Jourdan, $H .2004$. Experimental evidence of large-scale unicoloniality in the tramp ant Wasmannia auropunctata (Roger). Journal of Insect Behavior, 17, 263e271.

Leiser, J. K. 2003. When are neighbours 'dear enemies' and when are they not? The responses of territorial male variegated pupfish, Cyprinodon variegatus, to neighbours, strangers and heterospecifics. Animal Behaviour, 65, 453e462.

Lenoir, A., Nowbahari, E., Quérard, L., Pondicq, N. \& Delalande, C. 1990. Habitat exploitation and intercolonial relationships in the ant Cataglyphis cursor (Hymenoptera, Formicidae). Acta Oecologica, 11, $3 \mathbf{e} 18$.

Lenoir, A., Fresneau, D., Errard, C. \& Hefetz, A. 1999. Individuality and colonial identity in ants. In: Information Processing in Social Insects (Ed. by C. Detrain, J. L. Deneubourg \& J. Pasteels), pp. 219e 237. Basel: Birkhäuser-Verlag.

Lenoir, A., Hefetz, A., Simon, T. \& Soroker, V. 2001. Comparative dynamics of gestalt odour formation in two ant species Camponotus fellah and Aphaenogaster senilis (Hymenoptera: Formicidae). Physiological Entomology, 26, 275 e283.

Levings, S. C. \& Franks, N. R. 1982. Patterns of nest dispersion in a tropical ground ant community. Ecology, 63, 338e344.

López, P. \& Martín, J. 2002. Chemical rival recognition decreases aggression levels in male Iberian wall lizards, Podarcis hispanica. Behavioral Ecology and Sociobiology, 51, 461e465.

Mercier, J.-L., Lenoir, A. \& Dejean, A. 1997. Ritualized versus aggressive behaviours displayed by Polyrhachis laboriosa (F. Smith) during intraspecific competition. Behavioural Processes, 41, 39e50.

Michener, G. 1979. Spatial relationships and social organization of adult Richardson's ground squirrels. Canadian Journal of Zoology, $57,125 \mathbf{e} 139$.

Nichols, B. J. \& Sites, R. W. 1991. Ant predators of founder queens of Solenopsis invicta (Hymenoptera: Formicidae) in central Texas. Environmental Entomology, 20, 1024e1029.

Ozaki, M., Wada-Katsumata, A., Fujikawa, K., Iwasaki, M., Yokohari, F., Satoji, Y., Nisimura, T. \& Yamaoka, R. 2005. Ant nestmate and non-nestmate discrimination by a chemosensory sensillum. Science, 309, 311e314.

Pfeiffer, M. \& Linsenmair, K. E. 2001. Territoriality in the Malaysian giant ant Camponotus gigas (Hymenoptera/Formicidae). Journal of Ethology, 19, 75e85.

Pirk, C. W. W., Neumann, P., Moritz, R. F. A. \& Pamilo, P. 2001. Intranest relatedness and nestmate recognition in the meadow ant Formica pratensis (R.). Behavioral Ecology and Sociobiology, 49, 366e374.

Provost, E., Rivière, G., Roux, M., Morgan, E. D. \& Bagnères, A. G. 1993. Change in the chemical signature of the ant Leptothorax lichtensteini Bondroit with time. Insect Biochemistry and Molecular Biology, 23, 945e957.
Quinn, G. P. \& Keough, M. J. 2002. Experimental Design and Data Analysis for Biologists. Cambridge: Cambridge University Press.

Rosell, F. \& Bjorkoyli, T. 2002. A test of the dear enemy phenomenon in the Eurasian beaver. Animal Behaviour, 63, 1073e1078.

Ryti, R. T. \& Case, T. J. 1986. Overdispersion of ant colonies: a test of hypotheses. Oecologia, 69, 446e453.

Sanada-Morimura, S., Minai, M., Yokoyama, M., Hirota, T., Satoh, T. \& Obara, Y. 2003. Encounter-induced hostility to neighbors in the ant Pristomyrmex pungens. Behavioral Ecology, 14, 713e718.

Skinner, G. J. 1980. Territory, trail structure and activity patterns in the wood-ant, Formica rufa (Hymenoptera: Formicidae) in limestone woodland in north-west England. Journal of Animal Ecology, 49, 381 e394.

Soroker, V., Vienne, C. \& Hefetz, A. 1995. Hydrocarbon dynamics within and between nestmates in Cataglyphis niger (Hymenoptera: Formicidae). Journal of Chemical Ecology, 21, 365e378.

Soroker, V., Fresneau, D. \& Hefetz, A. 1998. Formation of colony odor in ponerine ant Pachycondyla apicalis. Journal of Chemical Ecology, 24, 1077e1090.

Suarez, A. V., Tsutsui, N. D., Holway, D. A. \& Case, T. J. 1999. Behavioral and genetic differentiation between native and introduced populations of the Argentine ant. Biological Invasions, 1, $43 \mathbf{e} 53$.

Suarez, A. V., Holway, D. A., Liang, D. S., Tsutsui, N. D. \& Case, T. J. 2002. Spatiotemporal patterns of intraspecific aggression in the invasive Argentine ant. Animal Behaviour, 64, 697e708.

Thomas, M. L., Parry, L. J., Allan, R. A. \& Elgar, M. A. 1999. Geographic affinity, cuticular hydrocarbons and colony recognition in the Australian meat ant Iridomyrmex purpureus. Naturwissenschaften, 86, 87e92.

Thomas, M. L., Payne-Makrisâ, C. M., Suarez, A. V., Tsutsui, N. D. \& Holway, D. A. 2006. When supercolonies collide: territorial aggression on an invasive and unicolonial social insect. Molecular Ecology, 15, 4303e4315.

Tsutsui, N. D., Suarez, A. V. \& Grosberg, R. K. 2003. Genetic diversity, asymmetrical aggression, and recognition in a widespread invasive species. Proceedings of the National Academy of Sciences, U.S.A., 100, 1078e1083.

Vander Meer, R. K. \& Morel, L. 1998. Nestmate recognition in ants. In: Pheromone Communication in Social Insects (Ed. by R. K. Vander Meer, M. Breed, M. Winston \& K. E. Espelie), pp. 79e103. Boulder, Colorado: Westview Press.

Wagner, D., Tissot, M., Cuevas, W. \& Gordon, D. M. 2000. Harvester ants utilize cuticular hydrocarbons in nestmate recognition. Journal of Chemical Ecology, 26, 2245e2257.

Ward, J. H. 1963. Hierarchical grouping to optimize an objective function. Journal of the American Statistical Association, 58, 236e244.

Wiernasz, D. C. \& Cole, B. J. 1995. Spatial distribution of Pogonomyrmex occidentalis: recruitment, mortality and overdispersion. Journal of Animal Ecology, 64, 519e527. 